\title{
Nurses' Communicating with Patients in Peripheral and Border Areas in Indonesia: A Phenomenology Study
}

\author{
Petrus Kanisius Siga Tage*®, Herliana Monika Azi Djogo®, Yulia M.K. \\ Letor $\odot$, Maria Yoanita Bina $\odot$, Rahmawati Rahmawati $\odot$ \\ Department of Nursing, Health Sciences Faculty, Universitas Citra Bangsa Kayu \\ Putih, Oebobo, Kupang East Nusa Tenggara, Indonesia
}

\begin{abstract}
Background: Communication is an important part of nursing care. However, Indonesian nurses still feel communication problems due to cultural and linguistic differences, especially in peripheral and border areas.

Purpose: This study explores the communication experience of nurses when providing services to patients in three peripheries and two border areas of Indonesia.

Methods: A phenomenological approach is used in this study. The purposive sampling technique was used to recruit 22 nurses in Indonesia's periphery and border areas to be involved in the study. The data collection process was carried out from August to October 2021. Data were collected through interviews using a semistructured questionnaire, and verbatim transcripts of audio-recorded interviews were analyzed using thematic analysis.

Results: This research resulted in four important themes, specifically: (1) difficulty in communicating, (2) emotional distress, (3) conflict and understanding, (4) lack of support for competency development.

Conclusion: The findings of this study increase the scientific understanding of the communication barriers of nurse in the culturally diverse periphery and border areas. The barriers encountered can be used by nursing managers to construct ineffective nurse communication problem-solving interventions. The main emphasis on solving communication problems should include continuing education and training support so that nurses' communication competence can be improved and applied in the service area based on the cultural and linguistic conditions of the patient.
\end{abstract}

Keywords: border; communication; cultural; nurse; peripheral; qualitative studies.

\section{Introduction}

Tage, P.K.S., Djogo, H.M.A., Letor, Y.M.K., Bina, M.Y., \& Rahmawati, R. (2021). Nurses' Communicating with Patients in Peripheral and Border Areas in Indonesia: A Phenomenology Study. Jurnal Keperawatan Padjadjaran, 9(3), 224-231. https://doi.org/10.24198/ jkp.v9i3.1931

Website

http://jkp.fkep.unpad.ac.id/index. php/jkp

This is an Open Access article distributed under the terms of the Creative Commons Attribution-NonCommercial 4.0 International License.

Communication is an important element to improve the quality of nursing care (Tindle et al., 2020). Effective communication flow is a tool for assessing patient needs and providing appropriate physical care, emotional support, and correct knowledge transfer and information exchange (Mistraletti et al., 2019; Tetteh et al., 2020; Wune et al., 2020). Failure to communicate effectively is a potential obstacle to the nursing care process. Studies show that ineffective patient-nurse communication results in increased hospital admissions, waste of resources, patient dissatisfaction, and lack of selfconfidence and stress for both the nurse and patient (Prip et al., 2019; Vermeir et al., 2018).

Ineffective communication in nursing services can be influenced by various factors such as differences in cultural values, experience levels, and individual personalities (Albagawi \& Jones, 2016). Communication is more difficult when patients and nurses have different cultural and linguistic values (Brunton \& Cook, 2018); thus, it can cause misunderstandings that can seriously impact the health and safety of the patient (Crawford et al., 2017). In the periphery of Indonesia, such as East Nusa Tenggara, which is directly 
adjacent to Timor Leste, cultural and linguistic diversity is very high. Linguistically, the geographic area of this archipelago displays cultural diversity and is a meeting place for languages belonging to the Austronesian and Papuan families with the use of up to 400 languages (Klamer \& Ewing, 2010).

The problem of communication barriers in the border areas of Indonesia and Timor Leste is related to the various languages that affect communication in society. There are at least five languages used, namely Tetun, Dawan, Indonesian, Portuguese, and English (Handoyo, 2011; Nahak, 2017; Taylor-Leech, 2009). Diverse cultures and languages will make it difficult for nurses to communicate in the nursing care process and potentially damage the quality of care. Therefore, this study was conducted to explore the problems related to communication between patients and nurses in the study area. Understanding nurses' experience is expected to be the basis for interventions to overcome communication barriers between nurses and patients.

This study aimed to reveal and describe the perceptions based on nurses' experiences in communicating with patients in Indonesia's periphery and border areas. This qualitative research focuses on answering the research question: "How is the experience of nurses communicating with patients from the periphery and border areas?"

\section{Methods}

This A phenomenological approach is used in this study. This research was conducted in the border areas of Indonesia and Timor Leste in the regions of Malaka, North Central Timor, and Atambua, while the outskirts include South Central Timor and Kupang Regency. The time of the study was from August to October 2021. Twenty-two participants who worked in border and periphery health facilities were selected using a purposive sampling technique. The inclusion criteria for selecting participants were nurses who had worked at least two years in their workplace when interviewed, nurses who were not on leave, and nurses who were not in a structural position and served patients directly. The saturation of the interview data was reached for the 22nd participant. The participant recruitment process is carried out by telephone. Informed consent was given verbally to participants before starting the interview process. Participants who agreed to be involved in the researchers were interviewed via the Zoom application. Ethical approval (No.021/ UN2.F12.D/HKP 02.04/2021) was obtained from the ethics committee of the Faculty of Nursing, University of Indonesia.

\section{Data collection}

Data was collected through semistructured in-depth interviews. Participants determined the time of the interview. Each participant was interviewed for 60 minutes. Two researchers conducted the interview process. The first researcher interviewed the first 12 participants, while the second researcher interviewed the remaining 10 participants. Interviews were conducted twice to ensure the correctness of the data submitted by the participants, the depth of the data, and to ensure that no data was missed during the interview process. At the end of the interview session, the two researchers discussed to ensure that the data met the desired research objectives. In the interview, when the researchers began to hear the same comments repeatedly, and data replication occured, the researchers assumed that data saturation had been reached and they stopped collecting information, and began to analyze what had been collected. The entire interview process was recorded in audio and video using Zoom application and transcribed word for word. Question guides were used to explore participants' experiences, such as: What does communication mean to you?, How do you communicate with patients? How do you respond when communicating with patients?, Do you experience communication barriers? The inclusion criteria set for the study participants were: nurses with a tenure of more than two years of not having a structural position and not on leave.

\section{Data Analysis}

To fulfill the research objectives, a thematic analysis approach was used in analyzing the data. The thematic analysis process follows several steps, such as (1) determining the initial code from the raw data, (2) looking for a suitable theme based on a set of codes that have been created, (3) reviewing theme suitability, (4) determining and naming the theme, and (5) producing the final report (Nowell et al., 2017). Efforts to ensure the validity of the data were carried out in several steps. Credibility was carried out by in-depth interviews twice by two researchers to participants at different times to obtain detailed information and ensure the truth of the data. Transferability was applied by writing down the findings in detail, clearly, systematically. Dependability was ensured through discussion and audit of data collected by five researchers, in turn, to find misinterpretations in the data. Confirmability is applied by keeping a diary related to the development of the research process, starting from determining the topic, methodology, data analysis, interpretation of results, and presenting conclusions.

\section{Trustworthiness}

Trustworthiness in this study was ensured through the steps suggested by Guba and Lincoln (1985), which included credibility, transferability, dependability, and confirmability (Denzin \& Lincoln, 2017). Credibility was achieved through in-depth interviews with participants by conducting two interviews, always checking initial findings and interpretations of the original data, and five researchers conducting continuous discussions to understand the data obtained immediately after the interview. Improved data transferability was achieved using a qualitative sampling method and 
Nurses' Communicating with Patients

Table 1. Demographic characteristics $(n=22)$

\begin{tabular}{lcc}
\hline Demographic characteristics & $\mathbf{n}$ & $\%$ \\
\hline Sex & 13 & 59 \\
Female & 9 & 40
\end{tabular}

Age (Years)

$\begin{array}{lll}25-35 & 6 & 27 \\ 36-45 & 7 & 31 \\ 46-55 & 5 & 22 \\ 56-65 & 4 & 18\end{array}$

$\begin{array}{lcl}\text { Educational background } & & 63 \\ 3 \text { Year Diploma } & 14 & 36\end{array}$

Length of the service (years)

$\begin{array}{lcr}2-10 & 11 & 50 \\ 11-20 & 6 & 27 \\ >20 & 5 & 22\end{array}$

$\begin{array}{lcc}\text { Marital status } & & 36 \\ \text { Single } & 8 & 63 \\ \text { Married } & 14 & \end{array}$

\section{Cultural Origin}

Flores 3

Sumba

Timor $\quad 12$

Alor

Sabu

Rote

1

2

2

$\begin{array}{lll}\text { Working Area } & & \\ \text { Rural Area } & 10 & 45 \\ \text { Border Line } & 12 & 54\end{array}$

Comunication Training

Yes

No

research design. The background of the research problem was based on previously published research and clearly defined the demographic data characteristics of the participants. Five researchers carry out dependability by jointly analyzing the data in a structured manner and interpreting the research results well so that they can make the same conclusions in the analysis. In addition, five researchers discussed, taking into account changes that might occur regarding the phenomenon under study as a result of a deeper understanding of the setting being studied. Confirmability was carried out through triangulation of researcher data, which included the use of several researchers during the interview process, keeping a diary related to research developments by determining topics, methodologies, data analysis, interpretation of
9

13

results, and presenting conclusions and the research team met regularly to discuss interpretations, codes, and theme. Furthermore, decision-making at each study stage was documented for tracking and follow-up actions.

\section{Results}

\section{Overview of the participants}

There were 22 participants involved in this study. Maximum data variation in interviews was conducted by selecting participants from heterogeneous groups. The participants involved in this study were 13 women, and nine men. The average age of the participants was dominated by the age of $36-45$ years as many as seven people The educational background of most participants 
was three-year diploma as many as 14 people. The longest working period was 2-10 years with 11 participants. Most marital status is married to as many as 14 people. The cultural background of most of the participants was from Timor, as many as 12 people. 12 participants work on the border line, and 13 participants have not received communication training (Table 1).

\section{Theme}

Analysis of interview data resulted in several themes. The themes underlying nurses' experience in communicating with patients in rural areas and borderlines include 1) communication difficulties, 2) emotional stress, 3) conflict and understanding, and 4) lack of support for competency development.

\section{Theme 1: Difficulty in Communicating}

Communication difficulties became the first and most prominent theme that emerged from the results of the interviews. The focus of this theme is the failure to understand the content of the speech "Most of our patients say something difficult for us to understand." (P8). Language inability and failure to change communication techniques are sub-themes of communication difficulties.

\section{Sub Theme 1: Not Proficient in Language}

Participants uttered seriously about the communication difficulties they face when dealing with patients. One participant who had worked for four years from another island explained how he often met patients who had difficulty speaking Indonesian during work.

"I often have difficulty understanding the contents of what patients say because most of them use regional languages and cannot speak Indonesian." (P21)

\section{Sub Theme 2: Failed to Change Style of Communication}

When meeting patients who used a local language, they did not understand. Nurses approached the patient differently by communicating with their family or speaking slowly to the patient. However, this modified form of communication approach is considered a failure by almost all participants to solve the problem of communication barriers between nurse and patient.

"When we meet patients who cannot speak Indonesian, we try to speak slowly to them or use their families as a communication bridge. However, it still feels difficult because most of the patients' families cannot speak Indonesian" (P17).

\section{Theme 2: Emotional Distress}

Failure to establish communication with patients put nurses in a difficult state with a confused and unstable mind. Many of the participants in the study appeared to be disturbed by the emotional and psychological distress of their communication with patients. Stress occured because of an impulse of worry, fear, frustration, and helplessness. One participant expressed fear that when they were unable to communicate, they would give the wrong nursing intervention and injure the patient.

"Sometimes, I feel afraid when I will give action to patients because they do not convey the health conditions they feel due to language barriers" (P12). The effect of emotional distress when caring for patients who experience communication barriers is analyzed in the sub-themes below.

\section{Sub Theme 1: Worry}

Many participants expressed concerns about their ability to solve problems and the effects of their actions when patients could not understand the instructions they were given due to communication barriers. One of the diploma graduate participants who had worked for two years expressed his experience:

"I worry when patients fail to understand the explanation I give.... Sometimes I feel like they are fine, stable, and getting better, but I always wonder if they'll be okay when I come home. One of my patients once came home in good condition, but he died when he was home a week later. I was afraid it would happen again." (P6)

\section{Sub Theme 2: Frustration}

The inability to communicate during the care process can increase the nurse's frustration, especially when the nurse cannot grasp the patient's intentions. One participant in the study reported, "I don't know what I'm going to do." (P21). They expressed frustration at realizing their responsibility to care for sick patients.

"Maybe the emotions of anger and frustration go hand in hand. Several times we try to invite patients to communicate, but they seem confused, and I also don't get the message they convey." (P8)

\section{Sub Theme 3: Helplessness}

During the interview, most participants expressed helplessness and an inability to solve problems and achieve goals. Participants who cannot identify the problem the patient complained about may experience a more intense feeling of helplessness. They feel unable to provide their patients with what they need.

"We work in an area with an underdeveloped society, and although leaving this workplace is not easy, I also can't think of a better way to cope with the situation I experience in communicating with patients." (P11)

\section{Theme 3: Conflict and Understanding}

A person experiences stress when they do not have the ability or resources when faced with an external stressor or are concerned that they do not have sufficient resources to deal with a problem. "Because of bad communication, it is easy to get angry with anyone at work." (P5). Poor communication at work can increase stress and 
pressure among nurses. This conflict, whether actual or perceived, is caused by conflicts between needs, values, and interests, which result in disagreements. A comprehensive study of the impact of this conflict on nurses is discussed below.

\section{Sub-theme 1: Disagreements with the Patient's Family}

Some participants reported disagreement about the appropriate approach to patient care and the treatment options used to treat patients who refused treatment due to communication failures. Additionally, participants said that disagreements about care between themselves and the patient's family often made the nurse's role more difficult. One of the participants who treated TB patients explained:

"We often have much disagreement about which treatment to give. For example, in managing TB cases, the patient's family does not accept drugs because of side effects. In their understanding, using drugs causes patients to get worse. And we get blamed by the patient's family about the treatment we give." (P4)

\section{Sub-theme 2: Workload Misunderstanding with Supervisor}

and

Most of the participants reported that taking care of patients with language barriers made them work harder, which increased the workload. Participants explained that high workloads could change their relationship with the supervisor. Most of the misunderstandings between nurses and their supervisors occured because of their disproportionate workload.

"Sometimes, I disagree with my supervisor. They thought I could do everything myself when I took care of many patients and gave me extra tasks. They don't realize that it has affected me both mentally and physically." (P7)

\section{Theme 4: Lack of Competency Development Support}

As a result of cultural differences, nurses who serve patients with language barrier conditions need support for developing individual competencies to interact well while providing care to patients. Nurses who have adequate communication competence will find it easier to create a more appropriate approach to patients to improve the quality of care.

"If we want to go to school, it's like a donkey getting into a pinhole, and everything will be made difficult if we don't have an "Orang Dalam" (a term related to nepotism)." (P13). Specifically, the theme of the lack of support for competency development will be discussed into two sub-themes

\section{Sub-theme 1: Not Equipped with Sufficient Knowledge}

Participants in this study expressed that they were not equipped with adequate knowledge when dealing with communication problems in practice.
One participant who had worked at a hospital for eight years said:

"It's been a long time since I was accepted to work here. I have never received training on communication techniques with patients from different cultures. I've been working based on experience." (P20)

\section{Sub-theme 2: Difficult to get Permission to Continue education}

Continuing education includes planned learning experiences that improve nurses' attitudes, skills, and knowledge. Changes that occur in nursing need to be responded through good education for nurses to increase the competence of nurses in the organization. When nurses find it difficult to continue their education, they will find it difficult to adapt to work demands, which affects work professionalism, including the ability of nurses to improve their form of communication with patients. One participant who has worked for 12 years expressed the experience:

"The opportunities for education (continuing education) are minimal; when they want to apply for permission to continue their education, a complicated bureaucracy will limit us. If you do not have kinship connections with government people, it is not easy for you to continue your education." (P13)

\section{Discussion}

The findings of this study provide information about nurses' experiences in communicating with patients of different cultures in the periphery and border areas of Indonesia. The communication problems faced by the participants were; communication difficulties, emotional distress, conflict, and tension, lack of support for competency development.

Nurses who interact with patients from different cultures and languages must face constant difficulties and continue to provide services to patients. Studies conducted (Emaliyawati et al., 2020) in West Java show that cultural and linguistic differences can hinder patient and nurse communication. The participants also expressed feelings of chaos and instability related to their situation. Any changes in an emotional state in their interactions with patients quickly affect their relationships with patients' families and their supervisors, and it leads to conflict. The situation experienced by participants tends to occur because efforts to improve through increasing communication competence do not go well.

Conditions that hinder communication between patients and nurses in health care facilities are cultural and linguistic factors (Ali \& Watson, 2018; Kwame \& Petrucka, 2020). This study found that the participants expressed difficulty communicating with patients who spoke the local language and could not speak Indonesian. This finding is similar to other reports, which explain that nurses experience communication problems when dealing with patients from different cultural and linguistic backgrounds 
Tage, P.K.S., et al. (2021)

(Alshammari et al., 2019).

Communication difficulties can affect the emotional state of nurses, thereby quickly making their feelings seem chaotic and unstable. Participants expressed that they were worried about their condition because they failed to communicate effectively. Emotionally, the participants also expressed frustration due to failure to find the right solution to solve the patient's problem because of the obstruction of communication. Nurses' emotional disturbances generally occur due to the interaction process and the complexity of problems during the care process. Previous reports have found that working in difficult situations while caring for patients makes it easy for nurses to become emotionally stressed and handle their own emotions (Chan et al., 2019). Nurses need to be involved in emotions to construct their identity through relationships with themselves and patients. A nurse can use her emotions positively in the care process to improve the quality of care (Jiménez-Herrera et al., 2020).

The literature shows that conflicts between health care staff, patients, and families present burdens for individuals and the health care system, including fatigue, absenteeism, and higher employee turnover (M.-L. Wang \& Tsai, 2014). The conflict has been defined as a multidimensional construction, which involves a process in which two or more people have different views (Johansen, 2012). Conflicts can occur vertically between staff and patients or horizontally between nurses and their superiors.

In this study, misunderstanding between nurses and family members about treatment was caused by a failure to understand messages. These findings are in line with previous studies reporting that communication affects the effectiveness of nursing interventions (including treatment collaboration) (Goldsmith et al., 2019). In a multicultural area with apparent cultural differences, it is easy to conflict between the nurse and the patient's family due to differences in views about treatment (Van Keer et al., 2020).

Apart from tensions with their families, this research confirms the conflict between participants and their superiors due to the increased workload. A high workload is reported as a stressor for nurses (Faremi et al., 2019). Specifically, the stress experienced by nurses if they are not handled or if they do not receive positive support from their superiors will trigger a conflict (Kokoroko \& Sanda, 2019). When conflicts arise, nurses must utilize various social support channels and adopt appropriate coping tactics. Besides, nursing managers need to provide specific and clear supportive measures such as enabling flexible vacation arrangements that help nurses better balance life and work responsibilities or stay happy with what they are doing (M.-L. Wang \& Tsai, 2014). The organization of nurses' healthcare facilities needs to create a more friendly communication environment to adopt constructive interpersonal conflict management strategies (Chang et al., 2017).
The fourth theme identified in this study is the participant's expression of the lack of support for competency development. Nurses' communication skills are considered factors that influence nursepatient relationships, especially for the effectiveness of interactions between different cultures (ChungYan Chan \& Sy, 2016). Nurses who are not equipped with adequate communication knowledge will experience problems in their services. The study conducted by (Park et al., 2015) showed that nurses who regularly contact people from diverse backgrounds and have low communication skills have poor job satisfaction. Organizations need to provide an excellent system to increase nurses' knowledge of competencies. The best skills training and continuing education of nurses' inappropriate communication techniques will enable them to respond adequately and humanely to any condition complained of by patients.

Participants in this study also expressed their difficulties in continuing their education to a higher level because of the lack of support from the government. A good education will help improving nurse communication skills. Studies show educational interventions affect improving nurse competence (Gutiérrez-Puertas et al., 2020; Kerr et al., 2020). Governments and administrators of service facilities where nurses work need to think about the availability of educational programs within the geographic reach of students, the amount of time and money investment required to complete education, and consider future job prospects, potential income, and possible job satisfaction. It may also be considered for female nurses who wish to combine childcare with work. There is a strong relationship between quality nursing education and health outcomes. Therefore, nursing education is a fundamental component in health care reform, especially in peripheral and border areas. Quality nursing education enables nurses to become credible players in the future domestic and global health care labor market (C. C. Wang et al., 2016).

The limitations of this study include the small sample size and the limited number of nurses participating in a similar geographic area, namely on the mainland of the island of Timor. The scope of the research should be broadened to capture the more significant problem of nurse communication. Given the vast geographical conditions of the Indonesian archipelago and diverse cultural and linguistic demographic conditions, the findings of this research problem may differ in each of the periphery and border areas of Indonesia.

\section{Conclusion}

The findings of this study lead to several experiences of communication with patients that are felt by nurses in the border and periphery areas of Indonesia, namely: difficulty in communicating, emotional distress, conflict and tensity, lack of support for competency development. Considering 
Nurses' Communicating with Patients

the generalizability of these findings, administrators of health care facilities in the remote areas of Indonesia need to direct their interventions towards the development of targeted and sustainable nurse communication competencies. Besides, we recommend that the recruitment pattern of nurses should be based on the suitability of cultural backgrounds between nurses and patients to reduce communication gaps due to language and cultural differences in nursing services.

\section{Acknowledgments}

Special mention for the participants of this study who shared their time and experiences.

\section{References}

Albagawi, B. S., \& Jones, L. K. (2016). Quantitative exploration of the barriers and facilitators to nurse-patient communication in Saudia Arabia. Journal of Hospital Administration, 6(1), 16. https://doi.org/10.5430/jha.v6n1p16

Ali, P. A., \& Watson, R. (2018). Language barriers and their impact on provision of care to patients with limited English proficiency: Nurses' perspectives. Journal of Clinical Nursing, 27(5-6), e1152-e1160. https://doi.org/10.1111/ jocn. 14204

Alshammari, M., Duff, J., \& Guilhermino, M. (2019). Barriers to nurse-patient communication in Saudi Arabia: An integrative review. In BMC Nursing, 18(61). https://doi.org/10.1186/ s12912-019-0385-4

Brunton, M., \& Cook, C. (2018). Dis/Integrating cultural difference in practice and communication: A qualitative study of host and migrant Registered Nurse perspectives from New Zealand. International Journal of Nursing Studies, 83, 18-24. https://doi.org/10.1016/j. ijnurstu.2018.04.005

Chan, E. A., Tsang, P. L., Ching, S. S. Y., Wong, F. Y., \& Lam, W. (2019). Nurses' perspectives on their communication with patients in busy oncology wards: A qualitative study. PLOS ONE, 14(10). https://doi.org/10.1371/journal. pone.0224178

Chang, T. F., Chen, C. K., \& Chen, M. J. (2017). A study of interpersonal conflict among operating room nurses. Journal of Nursing Research, 25(6), 400-410. https://doi.org/10.1097/ JNR.0000000000000187

Chung-Yan Chan, J., \& Sy, P. Y. (2016). The relationships among personality, intercultural communication, and cultural self-efficacy in nursing students. Journal of Nursing Research, 24(4), 286-290. https://doi.org/10.1097/ jnr.0000000000000157

Crawford, T., Candlin, S., \& Roger, P. (2017). New perspectives on understanding cultural diversity in nurse-patient communication. Collegian, 24(1), 63-69. https://doi. org/10.1016/j.colegn.2015.09.001
Denzin, N. K., \& Lincoln, Y. S. (2017). The Sage Handbook of Qualitative Research (5th ed.). SAGE Publications.

Emaliyawati, E., Widiasih, R., Sutini, T., \& Rahayu, U. (2020). Nurses' reflections on challenges and barriers of communication in the Intensive Care Unit: A phenomenology study. Jurnal Keperawatan Padjadjaran, 8(1), 65-73. https:// doi.org/10.24198/JKP.V8I1.1190.G253

Faremi, F. A., Olatubi, M. I., Adeniyi, K. G., \& Salau, O. R. (2019). Assessment of occupational related stress among nurses in two selected hospitals in a city in southwestern Nigeria. International Journal of Africa Nursing Sciences, 10, 68-73. https://doi.org/10.1016/j.ijans.2019.01.008

Goldsmith, J. V., Wittenberg, E., Terui, S., Kim, H., \& Umi, S. (2019). Providing support for caregiver communication burden: Assessing the plain language planner resource as a nursing intervention. Seminars in Oncology Nursing, 35(4), 354-358. https://doi.org/10.1016/j. soncn.2019.06.007

Gutiérrez-Puertas, L., Márquez-Hernández, V. V., Gutiérrez-Puertas, V., Granados-Gámez, G., \& Aguilera-Manrique, G. (2020). Educational interventions for nursing students to develop communication skills with patients: Asystematic review. International Journal of Environmental Research and Public Health, 17(7), 2241. https://doi.org/10.3390/ijerph17072241

Handoyo, S. (2011). The State's geopolitics versus the local's concern, a case study on the land border between Indonesia and Timor-Leste in West Sector. In: Murgante, B., Gervasi, O., Iglesias, A., Taniar, D., Apduhan, B.O. (eds). Lecture Notes in Computer Science, vol 6782. Springer, Berlin, Heidelberg.

Jiménez-Herrera, M. F., Llauradó-Serra, M., Acebedo-Urdiales, S., Bazo-Hernández, L., Font-Jiménez, I., \& Axelsson, C. (2020). Emotions and feelings in critical and emergency caring situations: A qualitative study. BMC Nursing, 19(1), 60. https://doi.org/10.1186/ s12912-020-00438-6

Johansen, M. L. (2012). Keeping the peace. Nursing Management (Springhouse), 43(2), 50-54. https://doi.org/10.1097/01. NUMA.0000410920.90831.96

Kerr, D., Ostaszkiewicz, J., Dunning, T., \& Martin, P. (2020). The effectiveness of training interventions on nurses' communication skills: A systematic review. In Nurse Education Today, 89. https://doi.org/10.1016/j.nedt.2020.104405

Klamer, M., \& Ewing, M. C. (2010). The languages of East Nusantara: An introduction. Australian National Universit. https://doi.org/10.15144/ PL-618

Kokoroko, E., \& Sanda, M. A. (2019). Effect of workload on job stress of Ghanaian OPD nurses: The role of coworker support. Safety and Health at Work, 10(3), 341-346. https:// doi.org/10.1016/j.shaw.2019.04.002 
Kwame, A., \& Petrucka, P. M. (2020). Communication in nurse-patient interaction in healthcare settings in sub-Saharan Africa: A scoping review. In International Journal of Africa Nursing Sciences, 12. https://doi.org/10.1016/j. ijans.2020.100198

Mistraletti, G., Mezzetti, A., Anania, S., Ionescu Maddalena, A., Del Negro, S., Giusti, G. D., Gili, A., lacobone, E., Pulitanò, S. M., Conti, G., \& Bocci, M. G. (2019). Improving communication toward ICU families to facilitate understanding and reduce stress. Protocol for a multicenter randomized and controlled Italian study. Contemporary Clinical Trials, 86. https:// doi.org/10.1016/j.cct.2019.105847

Nahak, M. M. N. (2017). Language variation in the family of the community in the border of Timor Leste and Malaka regency. https:// linguistik.fib.ui.ac.id/wp-content/uploads/ sites/46/2018/01/141-149-IAV_MariaMagdalena-Namok-Nahak.pdf

Nowell, L. S., Norris, J. M., White, D. E., \& Moules, N. J. (2017). Thematic analysis. International Journal of Qualitative Methods, 16(1). https:// doi.org/10.1177/1609406917733847

Park, M. S., Jeoung, Y., Lee, H. K., \& Sok, S. R. (2015). Relationships among communication competence, self-efficacy, and job satisfaction in Korean nurses working in the emergency medical center setting. Journal of Nursing Research, 23(2), 101-108. https://doi. org/10.1097/jnr.0000000000000059

Prip, A., Pii, K. H., Møller, K. A., Nielsen, D. L., Thorne, S. E., \& Jarden, M. (2019). Observations of the communication practices between nurses and patients in an oncology outpatient clinic. European Journal of Oncology Nursing, 40, 120-125. https://doi. org/10.1016/j.ejon.2019.03.004

Taylor-Leech, K. (2009). The language situation in Timor-Leste. 10(1), 1-68. https://doi. org/10.1080/14664200802339840

Tetteh, L., Aziato, L., Mensah, G. P., VehviläinenJulkunen, K., \& Kwegyir-Afful, E. (2021). Burns pain management: The role of nurse- patient communication. Burns : Journal of the International Society for Burn Injuries, 47(6), 1416-1423. https://doi.org/10.1016/j. burns.2020.11.011

Tindle, K., David, A., Carlisle, S., Faircloth, B., Fields, J. M., Hayden, G., \& Ku, B. (2020). Relationship of the Built Environment on Nursing Communication Patterns in the Emergency Department: A Task Performance and Analysis Time Study. Journal of Emergency Nursing, 46(4), 440-448. https:// doi.org/10.1016/j.jen.2020.04.005

Van Keer, R. L., Deschepper, R., Huyghens, L., \& Bilsen, J. (2020). Preventing Conflicts Between Nurses and Families of a Multiethnic Patient Population During Critical Medical Situations in a Hospital. Journal of Transcultural Nursing, 31(3), 250-256. https:// doi.org/10.1177/1043659619859049

Vermeir, P., Blot, S., Degroote, S., Vandijck, D., Mariman, A., Vanacker, T., Peleman, R., Verhaeghe, R., \& Vogelaers, D. (2018). Communication satisfaction and job satisfaction among critical care nurses and their impact on burnout and intention to leave: A questionnaire study. Intensive and Critical Care Nursing, 48, 21-27. https://doi. org/10.1016/j.iccn.2018.07.001

Wang, C. C., Whitehead, L., \& Bayes, S. (2016). Nursing education in China: Meeting the global demand for quality healthcare. International Journal of Nursing Sciences, 3(1), 131-136). https://doi.org/10.1016/j.ijnss.2016.02.009

Wang, M.-L., \& Tsai, L.-J. (2014). Work-Family Conflict and Job Performance in Nurses. Journal of Nursing Research, 22(3), 200-207. https://doi.org/10.1097/jnr.0000000000000040

Wune, G., Ayalew, Y., Hailu, A., \& Gebretensaye, T. (2020). Nurses to Patients Communication and Barriers Perceived by Nurses at Tikur Anbessa Specilized Hospital, Addis Ababa, Ethiopia 2018. International Journal of Africa Nursing Sciences, 12. https://doi.org/10.1016/j. ijans.2020.100197 